\title{
The Study on the Path of Entrepreneurship Education of local Colleges in Zhejiang Culture
}

\section{Qiongqiu Chen}

\author{
Hangzhou Normal University Qianjiang College, Hangzhou, Zhejiang, China
}

\begin{abstract}
Keywords: Zhejiang culture, Entrepreneurship education, Path study, local Colleges
\end{abstract}
\begin{abstract}
Zhejiang culture is the spiritual wealth created by Zhejiang merchants in the long-term business practice. At the same time, it has obvious geographical color, and its spiritual and cultural connotation has important guiding significance to the contemporary college students' entrepreneurship education. This paper aims to analyze how to integrate the "Zhejiang culture" with rich entrepreneurial cultural characteristics into entrepreneurship education, and to provide reference for improving the level of entrepreneurship education in undergraduate colleges.
\end{abstract}

\section{The Definition and Connotation of Zhejiang Culture}

Zhejiang culture is the Zhejiang businessmen in the long-term entrepreneurial practice to create a common sense of the spirit of wealth, but also has a clear geographical color. Zhejiang culture has nurtured Zhejiang businessmen, created a Zhejiang economic miracle, produced a number of well-known Zhejiang businessmen, created a "Zhejiang model", "Zhejiang economy" and "Zhejiang phenomenon", and Zhejiang culture is the essence of its embodiment.

"Small broad" pragmatic spirit, self-improvement attitude of life. In the Zhejiang culture there are more pragmatic tendencies and fewer elements of virtual arrogance. "Zhejiang business sense from small start, from the operation of a button, a badge, a switch began step by step business. They inherited the predecessors ` can hold the micro-capital to self-breeding 'tradition, with tens of dollars , A few hundred dollars of the capital started, one by one to make money. They are born in the peasantry, is the real civilians, at the beginning of the business, in the country engaged in the local people look down on the next live, harvest tattered, playing cotton, shoes, but they never to engage in these labor ashamed, but self-improvement , In the struggle for self-reliance for the accumulation of experience, they have gone through thousands of miles of water, after thousands of hardships, said all sorts of words, trying to do everything possible, and finally earn thousands of money, a successful entrepreneur.

Witty sharp strategic vision, positive and steady political attitude. Although the cultural quality of Zhejiang is not high, but it has a keen insight into the market and ahead of the strategic vision, take the opportunity to capture, they can from an obscure little details to find a fortune, such as the advent of the euro, carefully Of the Zhejiang businessmen soon found that the size of the euro banknote than the average paper money to be large, the original kind of wallet are not fit the euro, so to produce a suitable wallet for the euro, the first opened in Europe, the euro wallet market. In politics, Zhejiang is not like the Huizhou merchants "will be pinned on officialdom" or as Beijing businessmen as "political flavor with political cards", not as far away from politics as the Guangdong business, Zhejiang has a sensitive political sense of smell and accurate Political decision-making, there are a lot of Zhejiang had drilled the policy loopholes, they believe that political contains a huge business opportunities, the introduction or change of a policy can cause a high degree of concern Zhejiang, many successful Zhejiang are more or less have a non-economic aura, such as outstanding entrepreneurs, party representatives, deputies, CPPCC members.

Advancing with the times the spirit of innovation, open broad international perspective. Zhejiang is the most active and most innovative group, they rarely rigidly adhere to the rules, always "rack their brains" to capture business opportunities, "racking their brains" to find the market gap, they can go beyond the constraints of time and space, "nothing" One of the largest market, such as Yuyao plastic production base, Dongxiang sweater market, Hailing leather city, Jiashan wood processing center. 
Zheshang's vision is not limited to a place, they tend to look into the country and even the world, Zhejiang products sold around the world, especially the birth of Zhejiang network, to the traditional Zhejiang brought a new weather, they use With the Internet, easy to achieve the global business to sell the world, to the traditional business into a new international form.

Honest and trustworthy business attitude, to the rich sense of responsibility. Honest and trustworthy is followed by Zhejiang business ethics, in the beginning of the original accumulation, Wenzhou "fake and shoddy" popular, but the Hangzhou martial arts door "fire Wenzhou shoes" incident burned up Zhejiang businessmen, they spontaneously put good quality, the "Integrity "word is really engraved in the milestone of the enterprise, and now there are ten people in Wenzhou have a" gold pen ", without any guarantee and mortgage, with their own signature can be in the bank to obtain tens of millions of dollars loan.

Personal self-awareness of personality, and the attitude of life and attitude. Personal autonomy is a major feature of Zhejiang culture, the spirit of Zhejiang is the most fundamental spirit of self-development, "the concept of individual autonomy in Zhejiang who highlighted the strong sense of the boss when the boss, this sense of performance for the entrepreneurial spirit, leading consciousness, in the cause of development always when the leader. Zhejiang people like to do the boss, because the boss can get the spirit of freedom, as long as the law is not willing to do anything, the spirit will always be their own master. "Money to do the boss, no money to do the boss", "can do the boss, can sleep on the floor", fully embodies the Zhejiang boss of the complex, independent cultural concept. However, there are still strong thoughts of harmonious mediocrity in Zhejiang's cultural character. They have strong tolerance and patience to the external environment and heterogeneous culture, which makes the Zhejiang people no matter where they go, regardless of the cultural character and customs of the local people. Which type, can live in harmony with them, in any unfamiliar or even exclusion of the cultural circle can maintain a strong survival of adhesion.

\section{The Significance of Zhejiang Merchants' Culture in Entrepreneurship Education}

Zhejiang is the most developed private economy in China, the most active private entrepreneurs in the socialist market economy in the birth and growth of a group of entrepreneurs and entrepreneurs groups, they formed the "Zhejiang" in the course of the practice of accumulation Deep culture of "Zhejiang culture", this culture has a natural entrepreneurial properties, which contains the spirit of self-reliance, pragmatic spirit, innovative spirit, pioneering spirit and team spirit is its core, supporting a generation after generation of Zhejiang continue to forge ahead. The same kind of culture on vocational colleges to carry out entrepreneurship education also has an important positive role.

Learning Zhejiang culture is conducive to students to form a positive entrepreneurial awareness. First conscious budding, will stimulate the development of action. For students of undergraduate institutions, how to better stimulate their entrepreneurial awareness is the first step in entrepreneurship education. And "dare to first, especially to entrepreneurship" is the majority of Zhejiang enterprises to all the way to the development of the fundamental. Many people think that the business of Zhejiang business is born with, they are highly sensitive to business opportunities, and in the entrepreneurial process is very good at grasping business opportunities, from the profit, in fact, good at the political sense of smell and business sense of organic combination Zhejiang is the real talent.

The essence of entrepreneurial activity is to grasp the opportunity for the undergraduate institutions to carry out entrepreneurship education, in addition to cultivating their budding business, to consciously enrich their own entrepreneurial knowledge, enhance their own business and pioneering spirit of innovation, but also to the students of the macroeconomic situation and policy-oriented education.

Learning Zhejiang culture is conducive to students to improve their entrepreneurial knowledge and ability. Entrepreneurship is a very high demand for individual comprehensive quality. In the understanding of the relevant national policies and regulations, financial and financial, marketing and other knowledge, but also must have a certain communication skills, unity and 
cooperation ability and management capabilities and other comprehensive quality. Therefore, the undergraduate students to entrepreneurship knowledge and ability to cultivate, is a comprehensive work. Practice shows that the more entrepreneurial cultural environment is good place, the more entrepreneurial enthusiasm to stimulate entrepreneurs, in addition to providing a good knowledge environment and information sources, the more important is through subtle ways to effectively enhance the entrepreneurial quality of entrepreneurs. Many Zhejiang businessmen are starting from the grassroots, they do not have the funds and technology, lack of professional knowledge, but they make full use of their own learning, devote themselves to a field, continue to learn innovation, and ultimately become the industry leader.

Learning Zhejiang culture is conducive to students to develop a sound entrepreneurial psychology. Most of the entrepreneurs are failing, success is accidental, unsuccessful is inevitable, how to withstand the failure of entrepreneurial failure and entrepreneurial process of great pressure is every entrepreneur must go through the process. And many of the students are experiencing the failure of college entrance examination, they doubt their own ability, not try, not innovation, for the future career development is also more confused, which are hindering the undergraduate college entrepreneurship education to carry out. And "do everything possible to do everything, say all the thousand words, traveled thousands of miles of water, gone through untold hardships," the entrepreneurial process has become the best annotations of the spirit of Zhejiang, through the undergraduate education in the course of education, Into the Zhejiang culture, can help them to establish a "born I will be useful" self-confidence and positive attitude of optimism, and by constantly learning excellent Zhejiang typical, to help students understand the difficult business process, to train them to overcome the difficulties courage.

\section{Problems of the Undergraduate college entrepreneurship education at present}

Zhejiang culture is a distinctive geographical characteristics of the businessman culture, is undoubtedly an important part of Zhejiang culture, is the tide of the socialist market economy in the birth and growth of entrepreneurs and entrepreneurs formed by the group of "Zhejiang "In the practice of the accumulation of the rich business culture, is an important cultural resources and spiritual strength. To carry out Zhejiang culture and education, mainly through the Zhejiang culture in the condensed "Zhejiang spirit" factors to influence and affect students, focusing on training and training of new business people with Zhejiang who have the spirit of quality and awareness for the future practitioners to lay a certain Cultural connotation and will character.

Undergraduate college is lack of understanding of the importance of Zhejiang cultural resources. Business culture connotation rich, its biggest advantage lies in the spiritual advantage. Although with the change of the times, Zhejiang business model, business model will follow the transformation, although some colleges and universities have begun to explore the new Zhejiang culture and education model, but for the Zhejiang spirit of understanding and perception there are some deviations, The recognition of the importance of Zhejiang cultural resources and the development of educational and educational activities are also lacking.

Zhejiang culture and education and vocational ability training have not yet effectively integrated. To carry out Zhejiang culture and education, both from the perspective of the construction of campus culture, or from the perspective of humanistic quality education, are very concerned about the cultural environment factors on the quality of students, this effect should be closely linked with the cultivation of students' professional ability.

In fact, while we focus on cultivating students' professional competence, we cannot achieve the effective integration of Zhejiang culture and education (mainly professional ethics and professionalism) and vocational skills education, and this is precisely Students and the entire school development potential and core competitiveness of the support point.

The practical teaching of Zhejiang culture and education needs to be solved urgently. Effectively carry out Zhejiang culture and education, is not only stay in the consciousness of the cultivation and spiritual development, but also reflected in the specific action, through field visits, 
their own practice so that students can personally perceive and practice the spirit of Zhejiang, But the current platform is still relatively lack of relevant construction.

\section{Research on the Path of Entrepreneurship Education in Universities}

Undergraduate colleges in the innovation and entrepreneurship education should be fully learn the "Zhejiang culture" rich connotation, through adhering to the campus culture important educational function, carry out "Zhejiang culture" education, focusing on "Zhejiang business spirit" and influence students, Through the campus environment, entrepreneurial courses, student activities, teachers, practice base "five in one" system engineering construction, to explore a rich cultural characteristics of the "Zhejiang culture" into the effective path of entrepreneurship education.

Creating "Zhejiang Culture" Campus Environment. The campus environment is the tangible carrier of the implementation of entrepreneurship education, which has a subtle influence on the cultivation of students' entrepreneurial consciousness and the entrepreneurial spirit. To this end, the college in the construction of the campus environment highlights the characteristics of Zhejiang culture, adhere to the "soft and hard", soft and hard environment pavilions, so that the majority of teachers and students in the work and study from time to time, everywhere Zhejiang culture. In the construction of soft environment:

Build all kinds of Zhejiang cultural propaganda carrier. Such as the construction of the campus site Zhejiang business culture network, in the college We Chat public number construction forum, in the newspaper to open up Zhejiang culture column, etc., for students to provide a understanding of Zhejiang culture and exchange learning experience a good platform.

Held a variety of Zhejiang culture photo exhibition and the "charm of Zhejiang business" story broadcast.

Setting up "Zhejiang culture" entrepreneurial courses. Curriculum is the core carrier of university personnel training, the implementation of entrepreneurship education must play the main channel of classroom teaching role. Through the active development of Zhejiang culture into the entrepreneurial education compulsory courses, elective courses or seminars, the establishment of entrepreneurial education curriculum group, the formation of distinctive characteristics of the entrepreneurial education curriculum system. Set up Zhejiang culture courses, universal Zhejiang entrepreneurial spirit. This course includes the development process of Zhejiang business and the unique connotation of Zhejiang culture, not only the explanation of theoretical knowledge but also the field visit of Zhejiang enterprises, and the students can better understand Zhejiang culture and its business Spirit has a good teaching effect.

Carrying out "Zhejiang culture" community activities. The colorful campus community activities are an important channel for cultivating students' entrepreneurial spirit of innovation and entrepreneurial ability. Invited Zhejiang business culture related research scholars, experts and excellent Zhejiang alumni, entrepreneurs to lectures, so that students in-depth understanding of Zhejiang business entrepreneurship; set up to promote the spirit of Zhejiang students for the purpose of the student community.

Organization Zhejiang culture site construction, held Zhejiang business spirit photo exhibition, the story of the exhibition, etc. held all kinds of business competition. Around the "Zhejiang culture" to carry out various types of community activities, to create a strong "respect business, business, pro-business, diligent business" atmosphere, to stimulate the entrepreneurial passion of college students, enhance the entrepreneurial awareness of college students, and promote student organization and coordination Ability, language skills, teamwork ability.

Relying on "Zhejiang", strengthen the teachers' team. Professional teachers are an important guarantee for entrepreneurship education, a direct impact on the implementation of entrepreneurship education and its effectiveness. At present, most of the teachers in undergraduate institutions do not have the experience of entrepreneurial practice, so in the start of entrepreneurship education can only be "on paper" theoretical knowledge to explain. In order to solve this problem, it requires team teachers to establish an open educational philosophy, through the study of learning and exchange to speed up the knowledge update, through the study of employment training to perceive Zhejiang, 
Zhejiang business. At the same time, based on Zhejiang cultural studies, according to the requirements of the form of teaching, hire professional teachers, experts and scholars and outstanding alumni entrepreneurs having professional background and research expertise both inside and outside the school. And carry out curriculum teaching, seminars and seminars, to build a unique education and teaching team.

To carry out a flexible and diverse Zhejiang culture of practical education .The essence of culture is the process of human practice and the accumulation process. The cultural practice of the undergraduate institutions is both systematic and concrete, and both the concept, the concept, the system, the mechanism, the operation, the use, the matters, the item and the institution manager, and the teacher, Student related. The life of the undergraduate institutions lies in the close combination of the region and the local, leaving the specific soil, the undergraduate education cannot take root, flowering, the results. Therefore, in the cultural practice of undergraduate colleges, combined with the regional economy and local needs, according to local conditions to carry out the work, but also stick to the character, the formation of personality. Zhejiang culture has a very typical practical significance, with the current economic and social development are closely linked, while the nature of the education of undergraduate education requires Zhejiang culture and education cannot just stay in the course of theoretical teaching, but also to do the theoretical education And the combination of extracurricular practice, including Zhejiang culture and education base construction, corporate field visits, professional practice base docking, network business attempt. To solve these problems requires the school to consider and integrate effective resources.

\section{References}

[1] Y.X. Han, Zhejiang culture research, Harbin map press, 2007, vol. 5, pp. 18-20.

[2] B.Liu, Study on the Cultural Foundation of Entrepreneurship Education in Colleges and Universities, Journal of Educational Development, 2013, vol. 19, pp. 63-66.

[3] Y.Ch. Shi, University of entrepreneurship education should do and what to do, Higher Engineering Education Research, 2013, vol. 3, pp. 81-85.

[4] H.L. Zhang, Oxford University Saide Business School Entrepreneurship Education, Foreign Education Research, 2008, vol. 11, pp. 30-34.

[5] J. Wang, Research on the Entrepreneurship Education of College Students Based on Zhejiang's Cultural Perspective, Zhejiang Youth College, 2013, vol. 2, pp. 40-43.

[6] X.T. Dai, Problems and Countermeasures of Entrepreneurship Education in Higher Vocational Education. Research on Continuing Education, 2011, vol. 9, pp. 32-34. 